Cite this: Phys. Chem. Chem. Phys., 2013,

\title{
Sieving di-branched from mono-branched and linear alkanes using ZIF-8: experimental proof and theoretical explanation $\dagger$
}

15, 8795

Received 5th December 2012, Accepted 5th April 2013

DOI: 10.1039/c3cp44381g

www.rsc.org/pccp

\author{
Alexandre F. P. Ferreira, ${ }^{\text {ab }}$ Marjo C. Mittelmeijer-Hazeleger, ${ }^{b}$ Miguel Angelo Granato, ${ }^{a}$ \\ Vanessa F. Duarte Martins, ${ }^{a}$ Alírio E. Rodrigues ${ }^{a}$ and Gadi Rothenberg ${ }^{* b}$
}

\begin{abstract}
We study the adsorption equilibrium isotherms and differential heats of adsorption of hexane isomers on the zeolitic imidazolate framework ZIF-8. The studies are carried out at $373 \mathrm{~K}$ using a manometric set-up combined with a micro-calorimeter. We see that the Langmuir model describes well the isotherms for all four isomers (n-hexane, 2-methylpentane, 2,2-dimethylbutane and 2,3-dimethylbutane). The linear and mono-branched isomers adsorb well, but 2,2-dimethylbutane is totally excluded. Plotting the differential heat of adsorption against the loading shows an initial plateau for $n$-hexane and 2-methylpentane. This is followed by a slow rise, indicating adsorbate-adsorbate interactions. For the di-branched isomers the differential heat of adsorption decreases with loading. To gain further insight, we ran molecular simulations using the grand-canonical Monte Carlo approach. Comparing the simulation and the experimental results shows that the ZIF framework model requires blocking of the cages, since 2,2-dimethylbutane cannot fit through the sodalite-type windows. Practically speaking, this means that ZIF-8 is a highly promising candidate for enhancing gasoline octane numbers at $373 \mathrm{~K}$, as it can separate 2,2-dimethylbutane and 2,3-dimethylbutane from 2-methylpentane. Our results prove the potential of ZIF-8 as a new adsorbent that can be employed in the upgrade of the Total Isomerization Process for the production of high octane number gasoline, by blending di-branched alkanes in the gasoline.
\end{abstract}

\section{Introduction}

Chemists and chemical engineers have long sought to use alkanes as feedstocks for fuels, plastics, solvents and pharmaceuticals. The major drawback has been that the bonds within alkane molecules are so strong that alkanes are generally unreactive. Yet, in recent years the development of new catalysts has opened new doors to the activation of resilient alkanes. A fine example is the hydrogenolysis of saturated hydrocarbons to generate high value chemicals and diesel-based hydrocarbons using more efficient catalysts, such as fibrous nano-silica supported ruthenium and tantalum hydride supported on MCM-41. ${ }^{1,2}$ Another important reaction is the alkylation of alkanes, which was discovered by

\footnotetext{
${ }^{a}$ Laboratory of Separation and Reaction Engineering, Associate Laboratory LSRE/LCM, Department of Chemical Engineering, Faculty of Engineering,

University of Porto, Rua Dr Roberto Frias, Porto, Portugal

${ }^{b}$ Van't Hoff Institute for Molecular Sciences, University of Amsterdam,

Science Park 904, Amsterdam, The Netherlands.E-mail: g.rothenberg@uva.nl; Web: http://hims.uva.nl/hcsc

† Electronic supplementary information (ESI) available. See DOI: 10.1039/ c3cp44381g
}

Ipatieff and Pines in $1932 .{ }^{3}$ Today, this reaction is highly relevant in the production of Fischer-Tropsch diesel for the transport industry, and is still an active research field. ${ }^{4}$ Alkylation and isomerization are the main reactions for converting $\mathrm{C}_{4}-\mathrm{C}_{6}$ paraffins to highoctane, branched alkane gasoline additives. The alkanes in the gasoline fraction of crude oil are mainly linear or monobranched, and must be converted into highly branched isomers.

Thus, the molecular separation of hexane isomers is a key step in gasoline enrichment and octane number enhancement. Traditionally, this is an area where both zeolites and metalorganic frameworks (MOFs) are well known. ${ }^{5-7}$ Especially zeolites are extensively studied in this context, due to their well-defined pores, the diameters of which are close to those of alkane molecules. ${ }^{7}$ The most studied structures for separating hexane isomers are ZSM-5, ${ }^{8-11}$ silicalite- $1,{ }^{11-22}$ zeolite beta, ${ }^{23-29}$ and mordenite. ${ }^{30-32}$ Compared to this, there are relatively few studies on applying MOFs for separating hexane isomers, mainly using UiO-66(zr), ${ }^{33} \mathrm{Zn}(\mathrm{BDC})(\mathrm{DABCO})_{0.5},{ }^{34,35} \mathrm{MIL}-47,{ }^{36}$ $\mathrm{Cu}$ (hfipbb)( $\mathrm{H}_{2}$ hfipbb) $)_{0.5},{ }^{37}$ and $\mathrm{Zn}(\mathrm{BDC})\left(4,4^{\prime} \text {-Bipy }\right)_{0.5}$ (MOF-508). ${ }^{38}$

The problem is that cleanly separating fuel-grade hexanes remains a challenge, particularly where the cut between 
monobranched and dibranched isomers is concerned. Here we report the discovery that zeolitic imidazolate framework 8 (ZIF-8) can separate even 2,2-dimethylbutane from 2,3-dimethylbutane. Using a manometric set-up combined with a micro-calorimeter, we show that the sieving radius of ZIF-8 is between 5.8 and $6.3 \AA$. This value is much higher than the usually reported $5.3 \AA{ }^{39}$ To the best of our knowledge, this is the first report that compares the adsorption isotherms of all four isomers. Moreover, we present the differential heats of adsorption of the four components, emphasizing the higher affinity of ZIF-8 for the linear and monobranched isomers, which was also translated by higher adsorption enthalpies. The gate opening effect, due to the flipping of the imidazole linkers, has been mimicked in molecular simulations using the well-established blocking strategy, which has the major advantage of being rather simple to implement. As our work deals with the fundamentals of adsorption on ZIFs, we give a short overview to enable all readers to place the results in the right context.

Zeolitic imidazolate frameworks (ZIFs) combine the properties of both zeolites and MOFs, such as high porosity, high surface area, thermal and chemical stability, and tuneable metal clusters and organic linkers. ${ }^{7,40,41}$ This gives a wide range of highly interesting structures. ZIF-8 has the formula $\mathrm{Zn}(\mathrm{mim})_{2}$ (where $\operatorname{mim}=2$-methylimidazole) with a sodalite-related type structure $^{41}$ (see Fig. 1). At $3.4 \AA$ diameter, the six-membered-ring pore windows of ZIF-8 are narrow, but the cages inside (11.4 diameter) are much larger. ${ }^{42}$ Thermogravimetric analyses of ZIF8 showed a gradual weight-loss of $28.3 \%$ when the temperature was increased from 298 to $723 \mathrm{~K}$, corresponding to the loss of guest species, then the structure was stable up to a temperature of $823 \mathrm{~K},{ }^{41}$ identical to the temperatures at which the structural collapse of zeolites takes place. ${ }^{43}$

Several studies addressed the chromatographic separation of hexane isomers using ZIF-8 as a stationary phase. Chang et al. ${ }^{7}$ reported that branched alkanes eluted much earlier than their linear analogues on a ZIF-8 coated capillary. Moreover, 2,2-dimethylhexane eluted even earlier than hexane and heptane, despite its higher boiling point. In traditional stationary phases such as $5 \%$-phenylmethylpolysiloxane, however, the elution followed the order of boiling points. ${ }^{7}$ Large-pore MOFs such as MOF- $5^{7}$ and MOF- $508^{38}$ also showed the traditional elution sequence. Even though the diameter of the ZIF-8 pore window is only $3.4 \AA$, the framework is flexible, with no sharp sieving at $3.4 \AA$ (methane can enter the pores). ${ }^{7,42,44}$ But bulkier branched
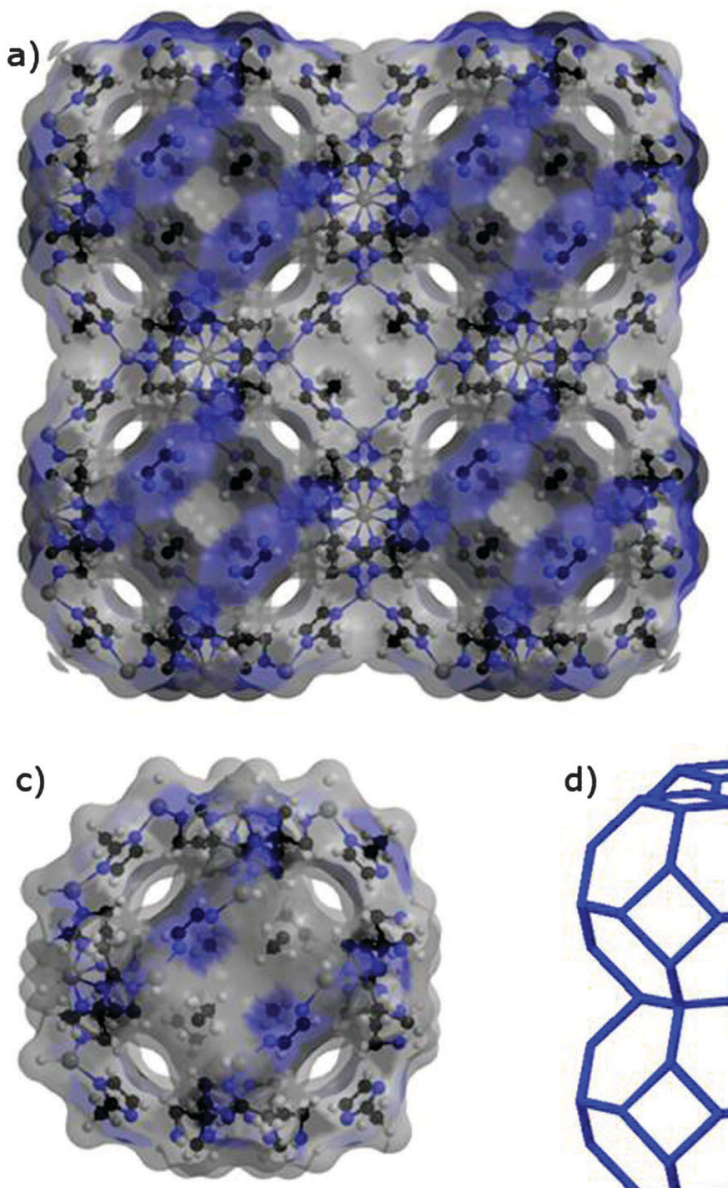

d)

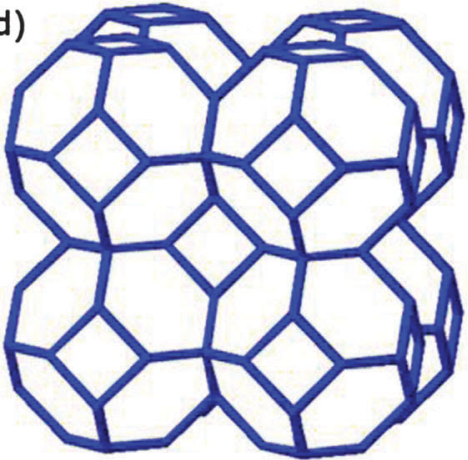

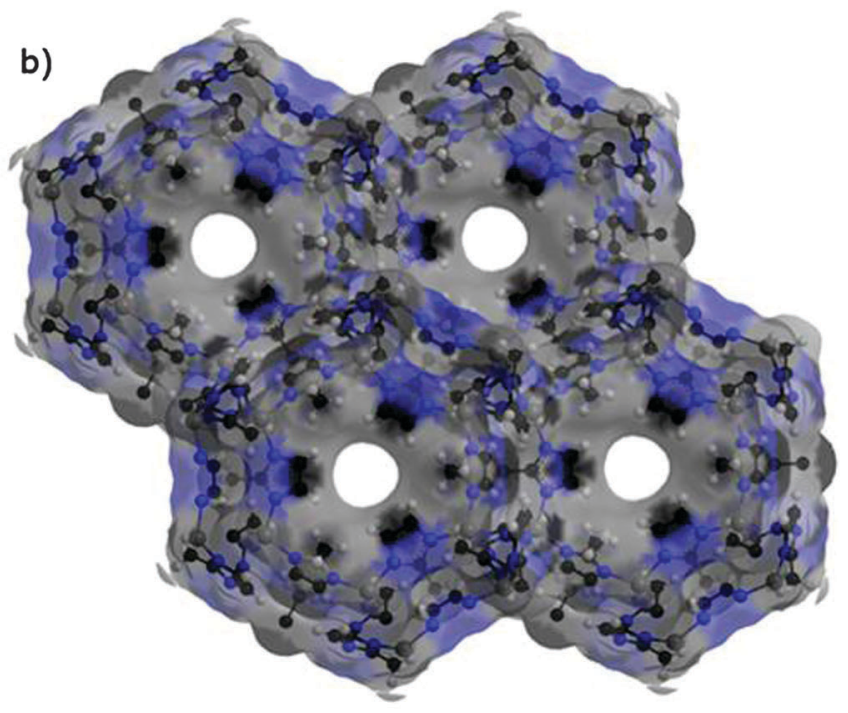

e)

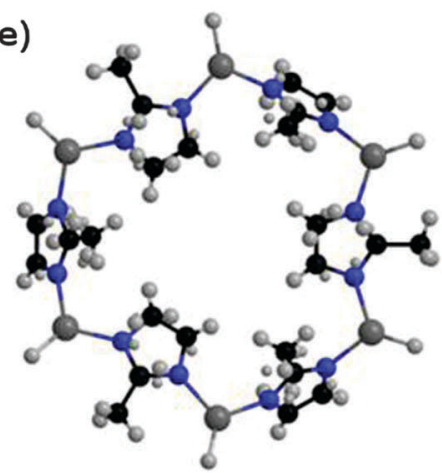

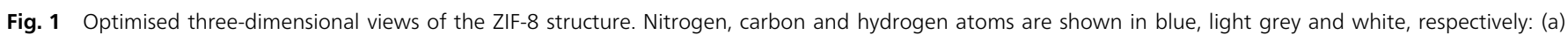
viewed along axis [001], (b) viewed along axis [111], (c) ZIF-8 sodalite-type cage, (d) SOD topology, and (e) 6-membered-ring window. 

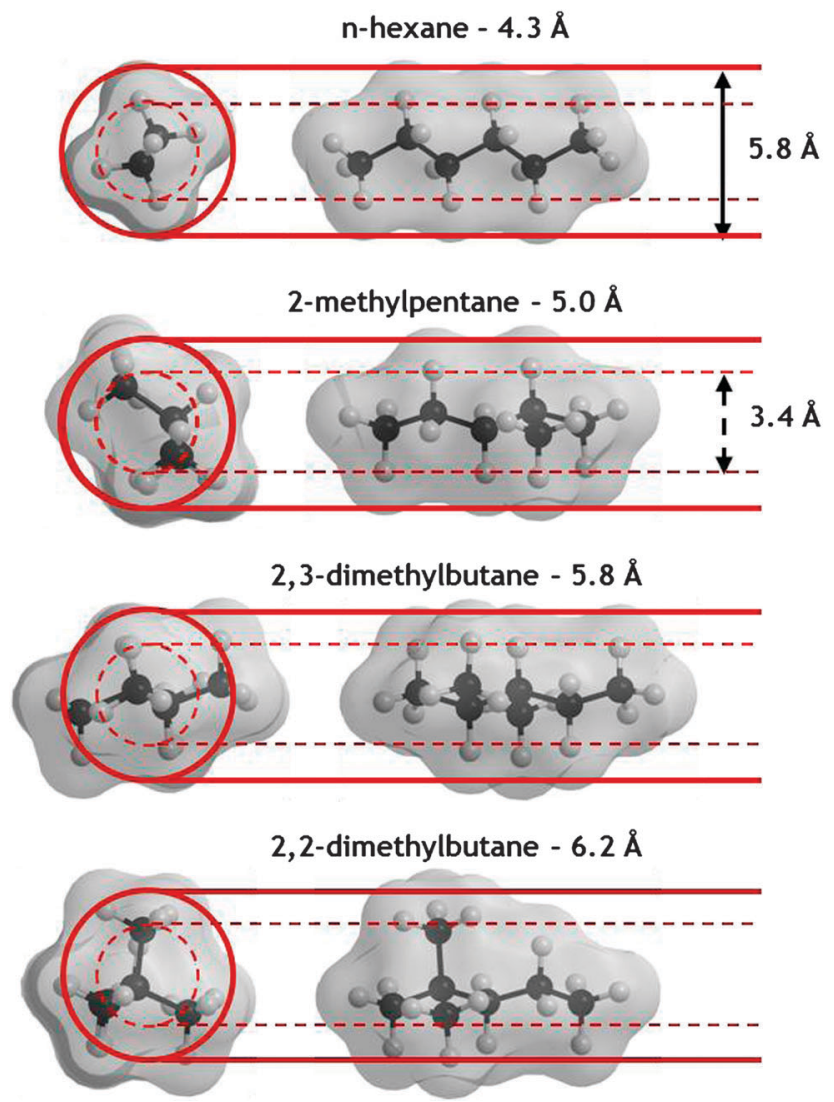

Fig. 2 Three-dimensional views and kinetic diameters of hexane isomers: (a) n-hexane, (b) 2-methylpentane, (c) 2,3-dimethylbutane and (d) 2,2-dimethylbutane. Carbon and hydrogen atoms are in light grey and dark grey, respectively. The optimized structures were generated using ChemBio3D Ultra (CambridgeSoft). The kinetic diameters were reported by Gobin et al. ${ }^{53}$

alkanes (see Fig. 2) cannot pass through the narrow pore windows, giving a shorter retention time. ${ }^{7}$ Elsewhere, Lu and Hupp ${ }^{45}$ observed that a ZIF-8 sensor displayed some chemical selectivity for linear $n$-hexane over the bulkier cyclohexane, ${ }^{45}$ and Luebbers et al. ${ }^{46}$ reported that branched alkanes (except i-butane) were excluded from the pores. Thus, 2-methylbutane eluted very quickly, with practically no retention compared to $n$-pentane. Similar results were seen for 2-methylheptane. ${ }^{46}$ More recently, Peralta et al. ${ }^{39}$ reported the separation of linear and branched hexane isomers by breakthrough experiments of binary mixtures in three different ZIF materials. They concluded that ZIF-8 acts as a molecular sieve: linear alkanes diffuse freely into the pores, while mono-branched alkanes are adsorbed under strong diffusional limitation, and di-branched alkanes are excluded from the pores. ${ }^{39}$ They also concluded that the effective pore size of ZIF-8 is comparable to the kinetic diameter of mono-branched alkanes, $5.3 \AA$. Since this is higher than the formal pore size of $3.4 \AA$, it means that the flexibility of the pore aperture in ZIF-8 is much higher than anticipated. ${ }^{39}$

Several molecular simulation studies address the adsorption properties of ZIFs for separating $\mathrm{CH}_{4}, \mathrm{CO}_{2}, \mathrm{H}_{2}$, and $\mathrm{N}_{2}$ binary mixtures, ${ }^{47-49}$ as well as ethane-ethene mixtures. ${ }^{50,51}$ The method used for methane adsorption on ZIF-8 reproduces well the experimental results, with slight overestimations. ${ }^{48,52}$
The above studies highlight the theoretical potential of ZIF-8 for separating hexane isomers. However, to prove this potential, we must obtain complete information on the adsorption equilibrium properties. To do this, we measured here the adsorption isotherms and differential heats of adsorption of $n$-hexane $\left(n-\mathrm{C}_{6}\right), 2$-methylpentane (2MP), 2,3-dimethylbutane (23DMB) and 2,2-dimethylbutane $(22 \mathrm{DMB})$ at $373 \mathrm{~K}$. The experimental isotherms were modelled using the Langmuir model. Additionally, Henry's constants were calculated for the four components. The results prove the potential of ZIF-8 as a new adsorbent in the Total Isomerization Process for the production of high octane number gasoline, by blending di-branched alkanes in the gasoline.

\section{Experimental}

\section{Materials and instrumentation}

The adsorptives used were $n$-hexane (99+\%, Merck), 2-methylpentane (99+\%, Acros), 2,3-dimethylbutane (98+\%, Acros) and 2,2-dimethylbutane (99+\%, TCI). These liquids were vaporized, and then fed into the system without any further treatment. ZIF-8 was the commercially available Basolite ${ }^{\circledR} \mathrm{Z}_{1200}{ }^{54}$ (BASF). The sample $(0.55 \mathrm{~g})$ was evacuated for $6 \mathrm{~h}$ at $573 \mathrm{~K}$, under a vacuum more than $2 \times 10^{-6}$ mbar. $\mathrm{N}_{2}$ adsorption isotherms were determined at $77 \mathrm{~K}$ on a Surfer instrument (Thermo Scientific) and evaluated using the BET equation. The equilibrium isotherms and differential heats of adsorption were determined using a dedicated manometric system (this system is described in detail elsewhere ${ }^{9}$ ).

Structure optimisations for Fig. 1 and 2 were generated using the ChemBio3D Ultra software (CambridgeSoft). Monte-Carlo simulations were carried out using the open source package RASPA 1.0 developed by Dubbeldam et al. ${ }^{55}$ This code was successfully applied in a large number of simulation studies. ${ }^{56-59}$ The simulations were performed using a $2 \times 2 \times 2$ supercell of dimensions $33.986 \times 33.986 \times 33.986 \AA^{3}$, typically using two million Monte Carlo steps.

\section{Procedure for adsorption equilibrium isotherms and differential heats of adsorption measurement}

The manometric introduction system was kept at $368 \mathrm{~K}$, while the transfer line and the sample holder inside of the microcalorimeter were kept at $373 \mathrm{~K}$ (Calvet C80, Setaram, see diagram and photo in Fig. 3). The experimental procedure comprises of measuring blanks, at $373 \mathrm{~K}$, for the different vapors (correcting for the non-ideality of the vapors). Blank measurements were run by introducing a known amount of gas into the empty sample holder, and then measuring the pressure. During the adsorption measurement it was considered that the adsorption equilibrium was achieved if the pressure changed less than $0.03 \mathrm{kPa}$ at a $100 \mathrm{~min}$ interval.

\section{Computational methods and models}

\section{Adsorption equilibrium and isotherm models}

The structure of ZIF-8 consists of large cages connected by sixmembered-ring windows in a sodalite topology. ${ }^{42}$ The windows 


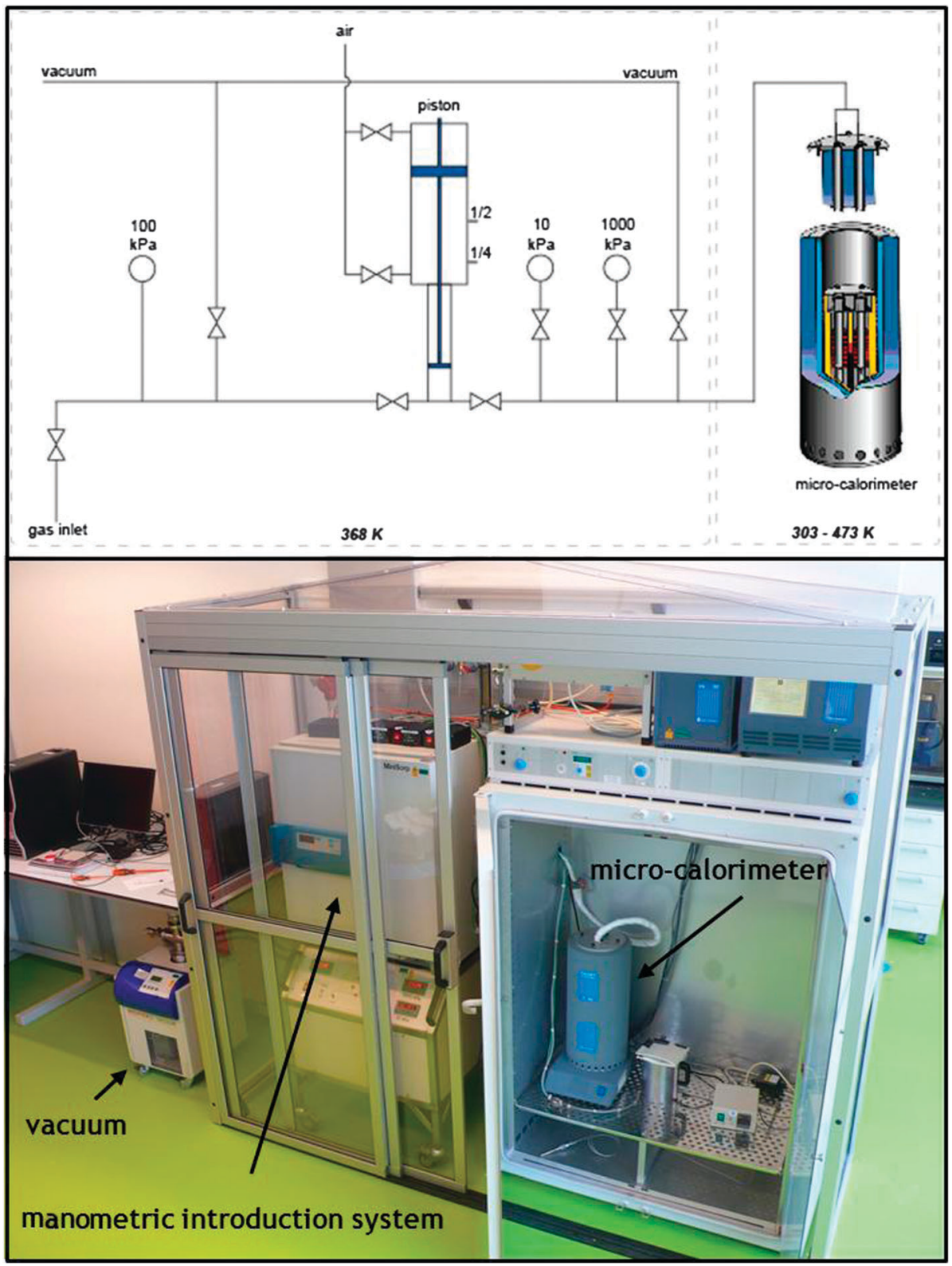

Fig. 3 Schematic and photograph of the experimental set-up, showing the micro-calorimeter in a thermostatic oven, the manometric introduction system, and the vacuum turbo-molecular pump. Photographs of detailed parts of equipment are presented in the ESI† - Fig. S4.

have a diameter of approximately $0.34 \mathrm{~nm} .^{42}$ This suggests that there is only one adsorption site. Therefore, a Langmuir model (eqn (1)) can suffice for describing the adsorption:

$$
n^{\mathrm{a}}=n_{\mathrm{sat}}^{\mathrm{a}} \frac{k p}{1+k p}
$$

here $n^{\mathrm{a}}$ is the loading (adsorbate concentration in the particles), $p$ is the pressure (adsorbate concentration in the gas phase), $n_{\text {sat }}^{\mathrm{a}}$ indicates the saturation loadings, and $k$ is the Langmuir adsorption equilibrium constant.

In the Henry's law region (low pressures) adsorption loading is directly proportional to the pressure (eqn (2), where $K_{\mathrm{H}}$ denotes the Henry constant).

$$
q=K_{\mathrm{H}} p
$$

Since the Langmuir model is thermodynamically consistent, we obtain eqn (3):

$$
K_{\mathrm{H}}=n_{\text {sat }}^{\mathrm{a}} k
$$

\section{Monte Carlo calculations}

The hexane isomers are described using a united-atom model, in which the $\mathrm{CH}_{n}$ groups are considered as a single interaction center without charge. In the Configurational BiasMonte Carlo (CBMC) algorithm, chains are built from a first united atom $\left(\mathrm{CH}_{n}\right.$ is considered to be the united atom for the alkane molecules in this study) placed at a random position. The second atom is added and a harmonic bonding potential is used for the bond length. Chains are then grown 
Table 1 LJ Potential parameters for united atoms and framework atoms

\begin{tabular}{lrr}
\hline & $\sigma(\AA)$ & $\varepsilon / k \mathrm{~B}(\mathrm{~K})$ \\
\hline United atom & & \\
$\mathrm{CH}_{3}$-sp & & \\
$\mathrm{CH}_{2}$-sp $^{3}$ & 3.76 & 108.00 \\
$\mathrm{CH}^{3} \mathrm{sp}^{3}$ & 3.96 & 56.00 \\
$\mathrm{C}-\mathrm{sp}^{3}$ & 4.68 & 17.00 \\
& 0.80 & 6.38 \\
Framework & & \\
$\mathrm{C}$ & & \\
$\mathrm{H}$ & 3.43 & 52.84 \\
$\mathrm{~N}$ & 2.57 & 22.14 \\
$\mathrm{O}$ & 3.26 & 34.72 \\
$\mathrm{Zn}$ & 3.12 & 30.19 \\
& 2.46 & 62.40 \\
\hline
\end{tabular}

segment by segment. The bond bending between three neighbouring beads is modelled by a harmonic cosine bending potential and the torsional angle is controlled by a Ryckaert-Bellemans potential. This bond length is fixed (1.53 ̊).

All non-bonded interactions are then described with the Lennard-Jones (LJ) 12-6 potential (eqn (4)),

$$
U\left(r_{i j}\right)=4 \varepsilon_{i j}\left[\left(\frac{\sigma_{i j}}{r_{i j}}\right)^{12}-\left(\frac{\sigma_{i j}}{r_{i j}}\right)^{6}\right]
$$

here $r_{i j}$ is the bead-bead separation, $\varepsilon_{i j}$ the LJ well depth, and $\sigma_{i j}$ the LJ diameter, all for beads $i$ and $j$. The LJ parameters are obtained by reproducing pure solvent properties, such as heats of vaporization and molecular volumes. Interactions between different pseudo-atoms are determined by the Lorentz-Berthelot mixing rules (eqn (5)),

$$
\left.\begin{array}{rl}
\sigma_{i j} & =\frac{1}{2}\left(\sigma_{i i}+\sigma_{i j}\right) \\
\varepsilon_{i j} & =\left(\varepsilon_{i i} \varepsilon_{j j}\right)^{\frac{1}{2}}
\end{array}\right\}
$$

Tables 1 and 2 give the forcefield parameters. The LJ parameters of the ZIF-8 framework were taken from the UFF forcefield. Potential parameters for the adsorbates were taken from the TraPPE UA forcefield. Details of the force fields are found in Rappe et al., ${ }^{60}$ Martin and Siepmann, ${ }^{61}$ and Calero et al. ${ }^{62}$ We use a truncated and shifted potential (cut-off radius = $12 \AA)$ without tail corrections. Since the adsorbate molecules are non-polar, electrostatic interactions were ignored. Guo et al. simulated the adsorption of methane/hydrogen on ZIFs using the same set of parameters. ${ }^{47}$

\section{Framework model and blocking of sodalite cages}

Because of the presence of long linkers rather than bridging $\mathrm{O}$ atoms, the pore cages in ZIF- 8 are about $11.6 \AA$ A. They are connected via small apertures with a diameter of $3.4 \AA$. Thus, even though a hexane isomer fits in the cage, it cannot enter it. As the CBMC method randomly grows a guest molecule atom by atom inside the cavities, hexane isomer molecules could actually be "loaded" into these cages. To prevent this, we blocked the cages artificially using the procedure outlined by Dubbeldam et al. ${ }^{63}$ Omitting this blocking could lead to false higher loadings, especially at low temperatures and/or high pressures (the favourable conditions for high adsorption loading).

\section{Results}

\section{Nitrogen equilibrium adsorption data}

The nitrogen adsorption isotherm is presented in Fig. 4. We see that the calculated micropore volume $\left(V_{\text {mic }} / \mathrm{cm}^{3} \mathrm{~g}^{-1}\right)$ is 0.73 . This volume was obtained by applying the Dubinin-Radushkevich (DR) equation to the $\mathrm{N}_{2}$ equilibrium data.

Applying the BET equation to the data gives a surface area value of $1800 \mathrm{~m}^{2} \mathrm{~g}^{-1}$. This value affirms the manufacturer's specification of $1300-1800 \mathrm{~m}^{2} \mathrm{~g}^{-1} \cdot{ }^{54}$ It also confirms that the activation procedure has regenerated the sample to its original state, removing any component (e.g. water) from the pores.

\section{Hexane isomer equilibrium adsorption data}

We then measured the adsorption equilibrium data of $n$-C6, 2-MP, 2,3-DMB and 2,2-DMB on ZIF-8 at $373 \mathrm{~K}$, for a pressure range from $0.01 \mathrm{kPa}$ to $100 \mathrm{kPa}$ (see Fig. 5).

Fig. 5 shows that ZIF-8 adsorbs $n$-hexane selectively. However, 2-methylpentane and 2,3-dimethylbutane present similar adsorption saturation loading, but with a lower Langmuir equilibrium constant (about half for the mono-branched isomer and twenty times lower for the di-branched isomer). Thus, we consider that the maximum capacity of the ZIF-8 cages is around $\sim 2.7 \mathrm{mmol} \mathrm{g}^{-1}$ (7.37 molecules (u.c. $)^{-1}$ ). The 2,2-dimethylbutane is almost excluded. Langmuir's model describes well the isotherms for all four isomers (see parameters in Table 3). Plotting the differential heat of adsorption against the loading (see Fig. 6) gives an initial plateau for $n$-hexane at around $42-44 \mathrm{~kJ} \mathrm{~mol}^{-1}$. This plateau is followed by a slow rise until about $60 \mathrm{~kJ} \mathrm{~mol}^{-1}$. We attribute this to increasing adsorbate-adsorbate interactions.

The differential heats of adsorption of 2-methylpentane present similar trends to $n$-hexane. For the di-branched isomers

\begin{tabular}{|c|c|c|c|c|}
\hline Bond & $U^{\text {bond }}=\frac{1}{2} k_{1}\left(r-r_{0}\right)^{2}, r_{0}=1.54 \AA$ & & & $\frac{k_{1}}{k_{\mathrm{B}}}=96500 \mathrm{~K} \AA^{-2}$ \\
\hline Bend & $U^{\text {bend }}=\frac{1}{2} k_{\theta}\left(\cos \theta-\cos \theta_{0}\right)^{2}, \theta_{0}=114^{\circ}$ & & & $\frac{k_{\theta}}{k_{\mathrm{B}}}=62500 \mathrm{~K} \mathrm{rad}^{-2}$ \\
\hline Torsion & $U^{\text {torsion }}=\sum_{n=0}^{5} \eta_{n} \cos ^{n} \varphi, \frac{\eta_{n}}{k_{\mathrm{B}}}=$ in $\mathrm{K}$ & & & \\
\hline$\eta_{0}$ & $\eta_{1}$ & $\eta_{3}$ & $\eta_{4}$ & $\eta_{5}$ \\
\hline 1204.654 & -357.854 & -1944.666 & 715.690 & -1565.572 \\
\hline
\end{tabular}

Table 2 Intramolecular parameters for the united atom (UA) force field 


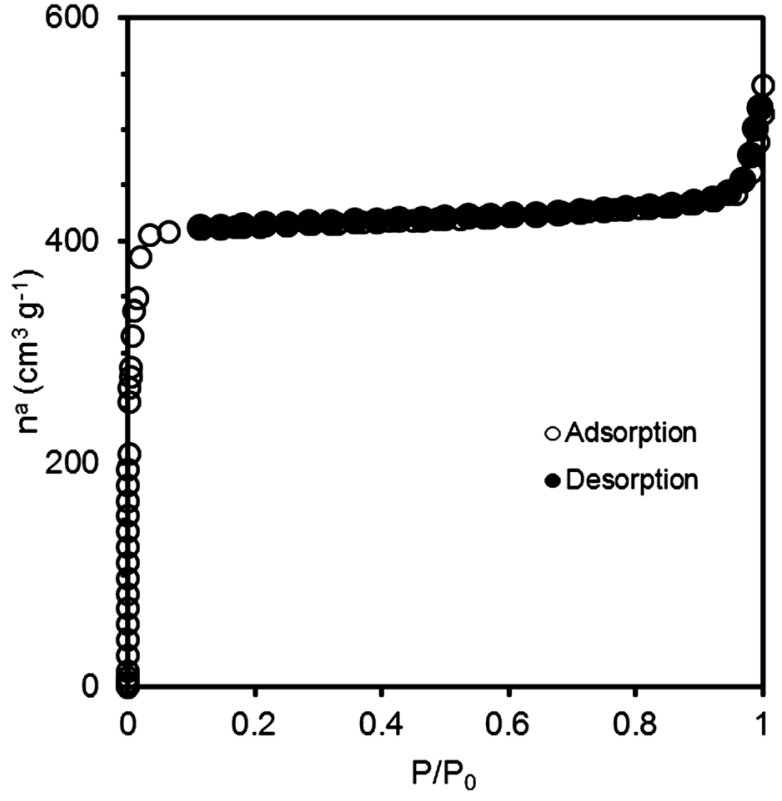

Fig. $4 \quad \mathrm{~N}_{2}$ adsorption isotherm on ZIF-8 at $77 \mathrm{~K}$.

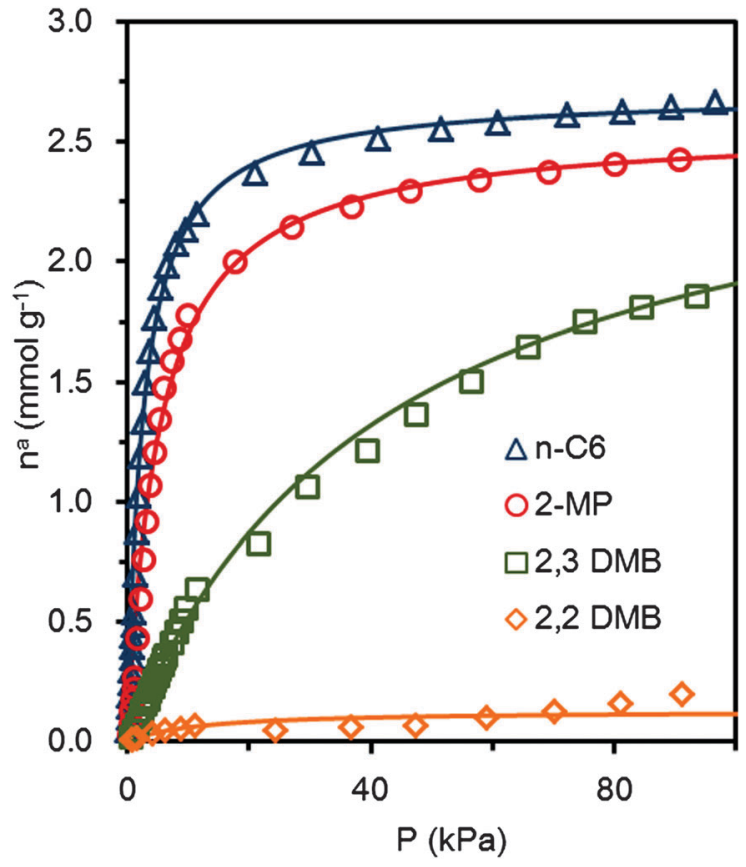

Fig. 5 Hexane isomer adsorption isotherms, on ZIF-8, at $373 \mathrm{~K}: \triangle$ : $n$-hexane, $\mathrm{O}$ : 2-methylpentane, $\square:$ 2,3-dimethylbutane, and $\diamond$ : 2,2-dimethylbutane. The curves show the Langmuir model fit for each isotherm, calculated using eqn (1).

Table 3 Langmuir adsorption parameters of hexane isomers on ZIF-8 at $373 \mathrm{~K}$

\begin{tabular}{lll}
\hline & Parameters & \\
\cline { 2 - 3 } & $n_{\text {sat }}^{\mathrm{a}}\left[\mathrm{mmol} \mathrm{g}^{-1}\right]$ & $K\left[\mathrm{kPa}^{-1}\right]$ \\
\hline$n$-Hexane & 2.70 & 0.40 \\
2-Methylpentane & 2.57 & 0.20 \\
2,3-Dimethylbutane & 2.72 & 0.02 \\
2,2-Dimethylbutane & 0.13 & 0.09
\end{tabular}

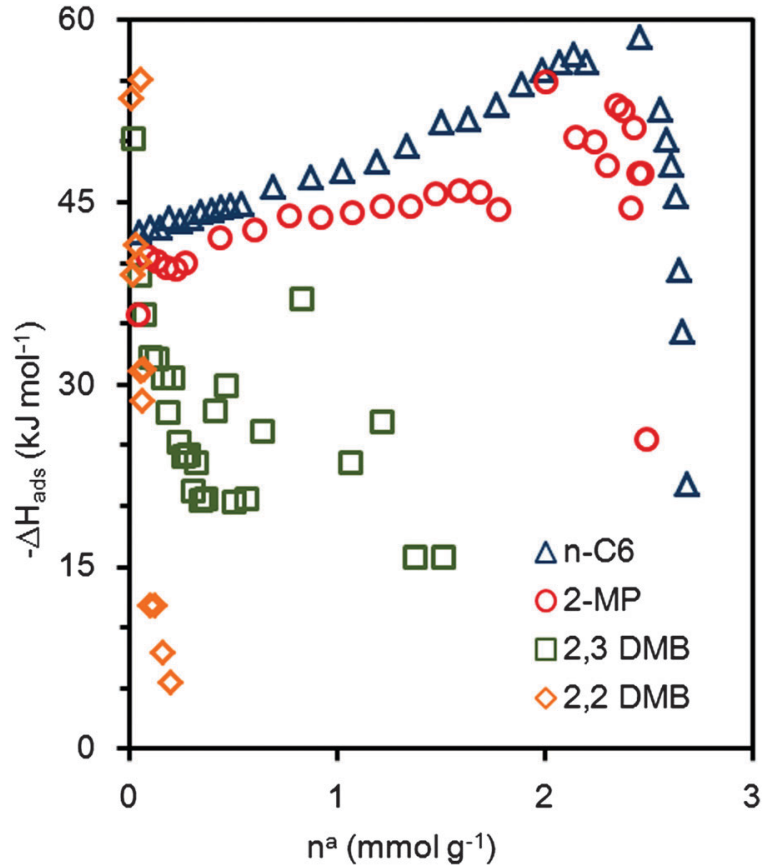

Fig. 6 Differential heats of adsorption for hexane isomers on ZIF-8 at $373 \mathrm{~K}$ : $\triangle: n$-hexane, $\bigcirc: 2$-methylpentane, $\square: 2,3$-dimethylbutane, and $\diamond: 2,2$-dimethylbutane.

the differential heat of adsorption decreases with loading. This decrease is sharper for the di-branched isomer. Overall, ZIF-8 shows a promising behaviour at $373 \mathrm{~K}$ for gasoline octane number enhancement, since it presents selectivity between 2-methylpentane and 2,3-dimethylbutane.

\section{Henry constants}

Table 4 presents the Henry constant values for the four isomers. These values were calculated using the slope of the line passing by the first data points of each isotherm (at least 8 points). This approach generally gives a good estimation for the Henry constant values. The values were compared with the value of the product $n_{\mathrm{sat}}^{\mathrm{a}} \times k$, to check the thermodynamic consistency of the model parameters. These results show that $n$-hexane has the highest affinity towards the adsorbent.

\section{Molecular simulations}

The molecular simulations were ran using the CBMC technique in the $\mu V T$ ensemble, where the chemical potential, temperature and volume are kept constant.

As Fig. 7a shows, if no blocking is used, all isomers quickly saturate the adsorbent. Almost no selectivity is observed.

Table 4 Henry constants for the hexane isomers, on ZIF-8, at $373 \mathrm{~K}$

\begin{tabular}{lll}
\hline & $K_{\mathrm{H}}\left[\mathrm{mmol} \mathrm{g}^{-1} \mathrm{kPa}^{-1}\right]$ & $n_{\text {sat }}^{\mathrm{a}} k\left[\mathrm{mmol} \mathrm{g}^{-1} \mathrm{kPa}^{-1}\right]$ \\
\hline n-Hexane & 0.56 & 1.07 \\
2-Methylpentane & 0.26 & 0.51 \\
2,3-Dimethylbutane & 0.06 & 0.06 \\
2,2-Dimethylbutane & 0.005 & 0.011
\end{tabular}



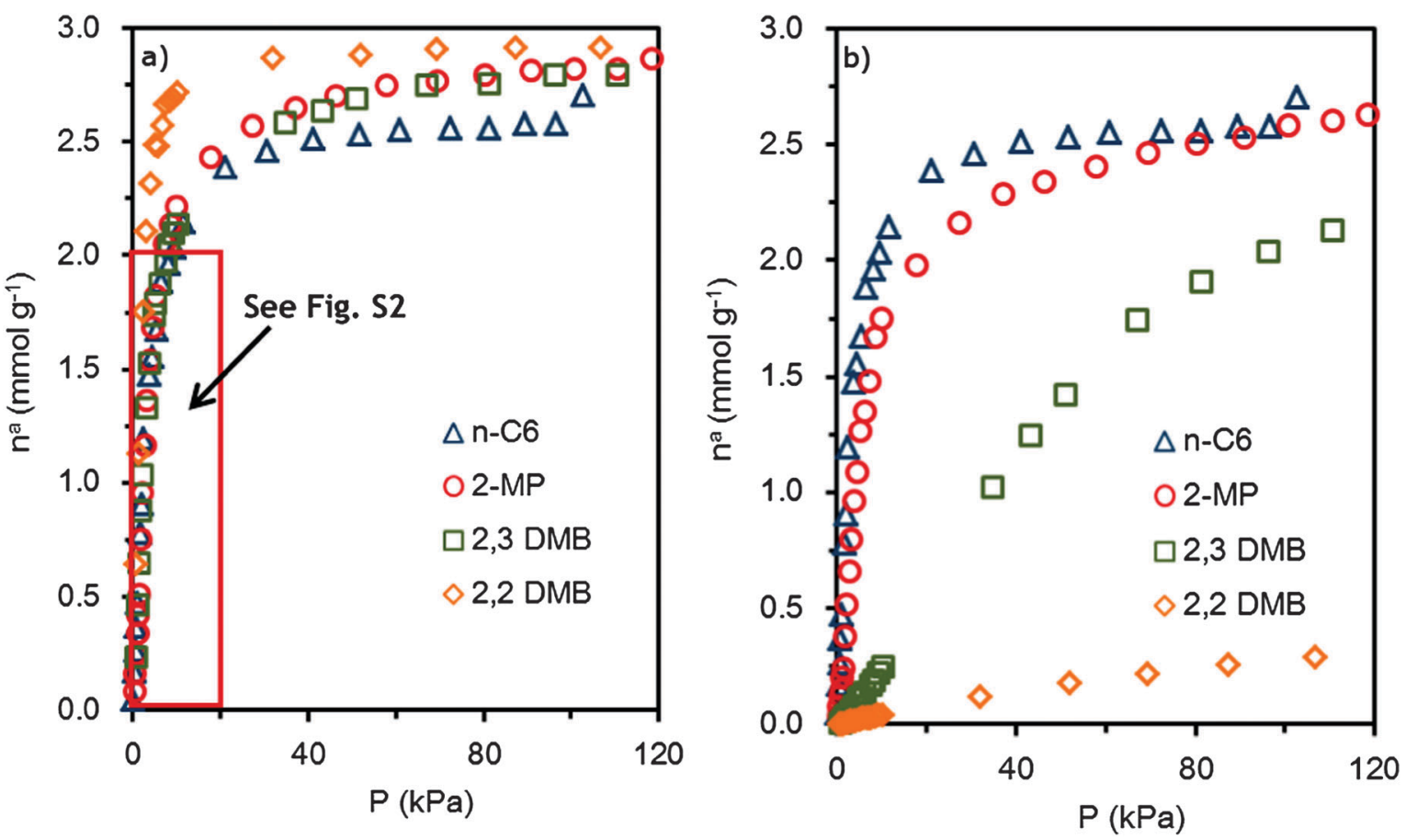

Fig. 7 Molecular simulation of the hexane isomer adsorption isotherms on ZIF-8 at $373 \mathrm{~K}$ : (a) without blocking and (b) with blocking. ( $\triangle$ : $n$-hexane, O: 2-methylpentane, $\square:$ 2,3-dimethylbutane, and $\diamond: 2,2$-dimethylbutane).

A zoom-in of the region with pressures up to $20 \mathrm{kPa}$ is included in the ESI $\dagger$ (Fig. S2). The maximum saturation is about $2.9 \mathrm{mmol} \mathrm{g}^{-1}$, corresponding to eight molecules per unit cell. When appropriate blocking is applied, the simulations correctly reproduce the experimental isotherms (see Fig. S3 ESI $\dagger$ ). The blocking strategy comprises rejection of all Monte Carlo moves that attempt to insert a molecule inside a certain radius. Fig. 8 shows a snapshot of the maximum adsorption loading of $n$-hexane in ZIF- 8 . The most favourable adsorption site for the $n$-hexane molecules is inside the cages. No adsorption occurs at the windows.

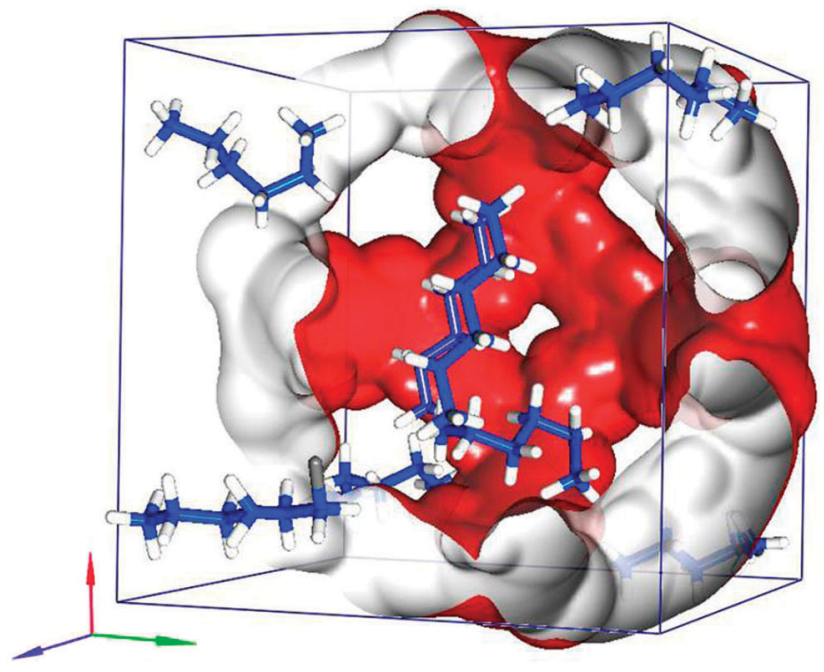

Fig. 8 Snapshot of adsorbed $n$-hexane in one ZIF-8 unit cell at $102 \mathrm{kPa}$.

\section{Discussion}

The capacity of $n$-hexane is 7.3 molecules per unit cell, corresponding to 22.11 carbon atoms per cage. This is in good agreement with the results of Bux et al., ${ }^{50}$ who reported a loading of 22 carbon atoms per cage for ethane in ZIF-8 at 298 K. Furthermore, applying the Van't Hoff equation to the values reported by Luebbers et al. (Table 1 in ref. 41) we get a Henry constant of $0.82 \mathrm{mmol} \mathrm{g}^{-1} \mathrm{kPa}^{-1}$ for $n$-hexane at $373 \mathrm{~K}^{46}$ This agrees with our own results (see Table 4). Using the Van't Hoff equation we can also derive the enthalpy of adsorption for $n$-hexane in ZIF-8, which equals $41.4 \mathrm{~kJ} \mathrm{~mol}^{-1}$. This differs slightly from the value reported by Luebbers et al. (37.5 $\left.\mathrm{kJ} \mathrm{mol}^{-1}\right)$. Nevertheless, both values are close to our experimental result, measured by microcalorimetry, of $42.4 \mathrm{~kJ} \mathrm{~mol}^{-1}$.

Peralta et $a l .{ }^{39}$ concluded, by means of binary vapour phase breakthrough experiments of $n$-hexane and 3-methylpentane, that the mono-branched isomer has a slow diffusion (three orders of magnitude lower than the $n$-hexane) and is also thermodynamically less favoured, with adsorption constant half of the linear isomer. The parameters obtained by fitting our data to a Langmuir isotherm model give an adsorption constant for $n$-hexane of $0.40 \mathrm{kPa}^{-1}$ and for 2-methylpentane of $0.20 \mathrm{kPa}^{-1}$. These values are in good agreement with the conclusions of Peralta et $a .^{39}$ Although we haven't performed up-take experiments to assess the diffusion constants, when we compare the equilibration times required for both isomers (see Tables in the ESI $\dagger$ ) we see that on average the 2-methylpentane takes about four times longer per point than the $n$-hexane. We attribute this to the slower diffusion of the mono-branched isomer. 
The effective adsorption of 2,3-dimethylbutane and exclusion of 2,2-dimethylbutane prove that the effective pore size of ZIF-8 is about $5.8 \AA$, up to a maximum of $6.3 \AA$. This is at least half an Ångström higher than the value presented by Peralta et al. ${ }^{39}$ and almost double of the reported window size (3.4 $\AA$ ).

Table 4 shows that the Langmuir model over-predicts the adsorption capacity at very low pressures for the $n$-hexane and 2-methylpentane. This is due to an inflection on the isotherm of those two isomers that happens at about $1 \mathrm{kPa}$ (see Fig. S1 in ESI $\dagger$ ). This might be due to a first step of adsorption in the cage windows at the surface of the crystals, since the inflection occurs at about $0.25-0.5 \mathrm{mmol} \mathrm{g}^{-1}$, which is similar to the total amount of 2,2-dimethylbutane adsorbed that can be attributed to surface adsorption. Practically speaking, the Langmuir model represents well the adsorption equilibrium of the four isomers, since for pressures above $2 \mathrm{kPa}$ the calculated adsorbed amount is close to the experimental value (note that in the regeneration step of the Total Isomerization Process, such low partial pressures are probably irrelevant).

The very low (yet still measurable) adsorption capacity of 2,2-dimethylbutane is attributed to "outer surface" adsorption. These molecules are too bulky to enter the cages, but it is possible that the ethyl group "anchors" in the window, leading to a certain amount of "external surface" adsorption that will depend on the crystallite size.

As we explained above, when no blocking is applied, the simulations show a slightly lower capacity for the linear isomer. The more compact 2,2-dimethylbutane presents the highest adsorption capacity. This is easily understood as the ZIF-8 cages are big when compared with the adsorbate molecules, and therefore, the packing effects (entropic) favour the di-branched isomers. This kind of effect was already observed in large-pore zeolites, such as mordenite. ${ }^{64}$ Nevertheless, we reasoned from experimental $v s$. simulation results that the adsorption behaviour of hexane isomers in ZIF-8 is not controlled by the cage accessible volume, but by the windows size and its "gate-opening" effect. This "gate-opening" effect is characteristic of some ZIF materials, as reported by van den Bergh et al. ${ }^{65,66}$ To reproduce the experimental results by CBMC simulations, we designed an appropriate blocking strategy. Blocking strategies are well known and simple to be employed. We obtained a good agreement between experimental and simulation results (see Fig. S3, ESI $\dagger$ ). Note that for simulation of the $n$-hexane isotherm no blocking was necessary. This might be because of the smaller kinetic diameter of $n$-hexane, therefore the gate-opening effect requires very low pressures for the $n$-hexane or even its adsorption is not affected by the window size at all.

\section{Conclusions}

From the adsorption equilibrium isotherms we conclude that ZIF-8 is selective for $n$-hexane and totally excludes the bulky 2,2-dimethylbutane. Moreover, our CBMC simulations with appropriate blocking predict well the adsorption of $n$-hexane on ZIF-8. ${ }^{67}$ ZIF-8 is a promising material for separating both linear and mono-branched alkanes from the di-branched ones, and therefore has a great potential for improving the Total Isomerization Process to obtain high-octane gasoline.

\section{Nomenclature}

$\Delta H_{\text {ads }} \quad$ Heat of adsorption

$k \quad$ Adsorption equilibrium constant

$K_{1}, K_{\theta} \quad$ Constants related to the bonded interactions: bond stretching and bond bending, respectively

$K_{\mathrm{B}} \quad$ Boltzmann's constant

$K_{\mathrm{H}} \quad$ Henry constant

$n^{\mathrm{a}} \quad$ Loading (adsorbate concentration in the particles)

$p \quad$ Pressure (adsorbate concentration in the gas phase)

$r \quad$ Bond length

$T \quad$ Temperature

$U \quad$ Potential energy related to the bond, bend and torsion potentials, respectively

V Volume

Greek letters

$\varepsilon \quad$ Characteristic energy in LJ potential

$\phi \quad$ Torsion angle

$\eta \quad$ Constants related to torsional configurations

$\mu \quad$ Chemical potential

$\theta \quad$ Bending angle

$\sigma \quad$ Characteristic distance in LJ potential

Subscripts

ads adsorption

sat saturation

Superscripts

bend Related to bending potential

bond Related to bonding potential

torsion Related to torsion potential

\section{Acknowledgements}

M.A.G. the Fundação para a Ciência e a Tecnologia (FCT) for financial support (post-doctoral grant SFRH/BPD/47432/2008). V.D.M. acknowledges a scholarship from project PTDCEQU/ ERQ/104413/2008. This work was partially supported by projects PTDC/EQU/ERQ/104413/2008 and Pest-C/EQB/ LA0020/2011, financed by FEDER through COMPETEPrograma Operacional Factores de Competitividade and by FCT-Fundação para a Ciência e a Tecnologia.

\section{Notes and references}

1 A. Fihri, M. Bouhrara, U. Patil, D. Cha, Y. Saih and V. Polshettiwar, ACS Catal., 2012, 2, 1425-1431.

2 V. Polshettiwar, F. A. Pasha, A. De Mallmann, S. Norsic, J. Thivolle-Cazat and J.-M. Basset, ChemCatChem, 2012, 4, 363-369.

3 G. Egloff and G. Hulla, Chem. Rev., 1945, 37, 323-399.

4 A. S. Goldman, A. H. Roy, Z. Huang, R. Ahuja, W. Schinski and M. Brookhart, Science, 2006, 312, 257-261.

5 G. Ferey, Chem. Soc. Rev., 2008, 37, 191-214. 
6 Contents and Chemical Science, ed. J. Long and O. Yaghi, The Royal Society of Chemistry, 2009.

7 N. Chang, Z. Y. Gu and X. P. Yan, J. Am. Chem. Soc., 2010, 132, 13645-13647.

8 A. F. P. Ferreira, M. Mittelmeijer and A. Bliek, Stud. Surf. Sci. Catal., 2004, 154, 1971-1977.

9 A. F. P. Ferreira, M. C. Mittelmeijer-Hazeleger and A. Bliek, Microporous Mesoporous Mater., 2006, 91, 47-52.

10 A. F. P. Ferreira, M. C. Mittelmeijer-Hazeleger and A. Bliek, Adsorption, 2007, 13, 105-114.

11 A. F. P. Ferreira, M. C. Mittelmeijer-Hazeleger, A. Bliek and J. A. Moulijn, Microporous Mesoporous Mater., 2008, 111, 171-177.

12 A. C. Dubreuil, E. Jolimaitre, M. Tayakout-Fayolle and A. Methivier, Ind. Eng. Chem. Res., 2008, 47, 2386-2390.

13 E. Jolimaitre, K. Ragil, M. Tayakout-Fayolle and C. Jallut, AIChE J., 2002, 48, 1927-1937.

14 E. Jolimaitre, M. Tayakout-Fayolle, C. Jallut and K. Ragil, Ind. Eng. Chem. Res., 2001, 40, 914-926.

15 K. Lettat, E. Jolimaitre, M. Tayakout and D. Tondeur, AIChE J., 2011, 57, 319-332.

16 T. J. H. Vlugt, W. Zhu, F. Kapteijn, J. A. Moulijn, B. Smit and R. Krishna, J. Am. Chem. Soc., 1998, 120, 5599-5600.

17 W. Zhu, F. Kapteijn and J. A. Moulijn, Phys. Chem. Chem. Phys., 2000, 2, 1989-1995.

18 W. Zhu, F. Kapteijn and J. A. Moulijn, Adsorption, 2000, 6, 159-167.

19 W. Zhu, F. Kapteijn and J. A. Moulijn, Microporous Mesoporous Mater., 2001, 47, 157-171.

20 W. Zhu, F. Kapteijn and J. A. Moulijn, Sep. Purif. Technol., 2003, 32, 223-230.

21 W. Zhu, F. Kapteijn, B. van der Linden and J. A. Moulijn, Phys. Chem. Chem. Phys., 2001, 3, 1755-1761.

22 W. Zhu, J. M. van de Graaf, L. J. P. van den Broeke, F. Kapteijn and J. A. Moulijn, Ind. Eng. Chem. Res., 1998, 37, 1934-1942.

23 P. S. Barcia, A. Ferreira, J. Gascon, S. Aguado, J. A. C. Silva, A. E. Rodrigues and F. Kapteijn, Microporous Mesoporous Mater., 2010, 128, 194-202.

24 P. S. Barcia, J. A. C. Silva and A. E. Rodrigues, Microporous Mesoporous Mater., 2005, 79, 145-163.

25 P. S. Barcia, J. A. C. Silva and A. E. Rodrigues, Ind. Eng. Chem. Res., 2006, 45, 4316-4328.

26 P. S. Barcia, J. A. C. Silva and A. E. Rodrigues, AIChE J., 2007, 53, 1970-1981.

27 P. S. Barcia, J. A. C. Silva and A. E. Rodrigues, Adsorpt. Sci. Technol., 2007, 25, 169-183.

28 P. S. Barcia, J. A. C. Silva and A. E. Rodrigues, Energy Fuels, 2010, 24, 5116-5130.

29 E. Garcia-Perez, P. S. Barcia, J. A. C. Silva, A. E. Rodrigues and S. Calero, Theor. Chem. Acc., 2011, 128, 695-703.

30 K. Huddersman and M. Klimczyk, AIChE J., 1996, 42, 405-408.

31 K. Huddersman, AIChE J., 1996, 42, 2990-2992.

32 J. M. van Baten and R. Krishna, Microporous Mesoporous Mater., 2005, 84, 179-191.
33 P. S. Barcia, D. Guimaraes, P. A. P. Mendes, J. A. C. Silva, V. Guillerm, H. Chevreau, C. Serre and A. E. Rodrigues, Microporous Mesoporous Mater., 2011, 139, 67-73.

34 P. S. Barcia, F. Zapata, J. A. C. Silva, A. E. Rodrigues and B. L. Chen, J. Phys. Chem. B, 2007, 111, 6101-6103.

35 D. Dubbeldam, C. J. Galvin, K. S. Walton, D. E. Ellis and R. Q. Snurr, J. Am. Chem. Soc., 2008, 130, 10884-+.

36 V. Finsy, S. Calero, E. Garcia-Perez, P. J. Merkling, G. Vedts, D. E. De Vos, G. V. Baron and J. F. M. Denayer, Phys. Chem. Chem. Phys., 2009, 11, 3515-3521.

37 L. Pan, D. H. Olson, L. R. Ciemnolonski, R. Heddy and J. Li, Angew. Chem., Int. Ed., 2006, 45, 616-619.

38 B. L. Chen, C. D. Liang, J. Yang, D. S. Contreras, Y. L. Clancy, E. B. Lobkovsky, O. M. Yaghi and S. Dai, Angew. Chem., Int. Ed., 2006, 45, 1390-1393.

39 D. Peralta, G. Chaplais, A. Simon-Masseron, K. Barthelet and G. D. Pirngruber, Ind. Eng. Chem. Res., 2012, 51, 4692-4702.

40 A. P. Cote and O. M. Yaghi, Abstr. Paper. Am. Chem. Soc., 2007, 233, 61.

41 K. S. Park, Z. Ni, A. P. Cote, J. Y. Choi, R. D. Huang, F. J. UribeRomo, H. K. Chae, M. O'Keeffe and O. M. Yaghi, Proc. Natl. Acad. Sci. U. S. A., 2006, 103, 10186-10191.

42 H. Bux, F. Y. Liang, Y. S. Li, J. Cravillon, M. Wiebcke and J. Caro, J. Am. Chem. Soc., 2009, 131, 16000-16001.

43 G. Cruciani, J. Phys. Chem. Solids, 2006, 67, 1973-1994.

44 W. Zhou, H. Wu, T. J. Udovic, J. J. Rush and T. Yildirim, J. Phys. Chem. A, 2008, 112, 12602-12606.

45 G. Lu and J. T. Hupp, J. Am. Chem. Soc., 2010, 132, 7832-7833.

46 M. T. Luebbers, T. J. Wu, L. J. Shen and R. I. Masel, Langmuir, 2010, 26, 15625-15633.

47 H. C. Guo, F. Shi, Z. F. Ma and X. Q. Liu, J. Phys. Chem. C, 2010, 114, 12158-12165.

48 J. Perez-Pellitero, H. Amrouche, F. R. Siperstein, G. Pirngruber, C. Nieto-Draghi, G. Chaplais, A. SimonMasseron, D. Bazer-Bachi, D. Peralta and N. Bats, Chem.-Eur. J., 2010, 16, 1560-1571.

49 A. Battisti, S. Taioli and G. Garberoglio, Microporous Mesoporous Mater., 2011, 143, 46-53.

50 H. Bux, C. Chmelik, R. Krishna and J. Caro, J. Membr. Sci., 2011, 369, 284-289.

51 H. Bux, C. Chmelik, J. M. van Baten, R. Krishna and J. Caro, Adv. Mater., 2010, 22, 4741-4743.

52 W. Zhou, H. Wu, M. R. Hartman and T. Yildirim, J. Phys. Chem. C, 2007, 111, 16131-16137.

53 O. C. Gobin, S. J. Reitmeier, A. Jentys and J. A. Lercher, J. Phys. Chem. C, 2011, 115, 1171-1179.

54 2-Methylimidazole zinc salt, MSDS sheet (online). SigmaAldrich Quimica SA, Madrid, Spain.

55 D. Dubbeldam, S. Calero, D. E. Ellis and R. Q. Snurr, RASPA 1.0: Molecular Software Package for Adsorption and Diffusion in (Flexible) Nanoporous Materials, 2009.

56 S. Calero, A. Martin-Calvo, S. Hamad and E. Garcia-Perez, Chem. Commun., 2011, 47, 508-510.

57 J. M. Castillo, T. J. H. Vlugt and S. Calero, J. Phys. Chem. C, 2008, 112, 15934-15939. 
58 J. M. Castillo, T. J. H. Vlugt and S. Calero, J. Phys. Chem. C, 2009, 113, 20869-20874.

59 A. García-Sánchez, C. O. Ania, J. B. Parra, D. Dubbeldam, T. J. H. Vlugt, R. Krishna and S. Calero, J. Phys. Chem. C, 2009, 113, 8814-8820.

60 A. K. Rappe, C. J. Casewit, K. S. Colwell, W. A. Goddard and W. M. Skiff, J. Am. Chem. Soc., 1992, 114, 10024-10035.

61 M. G. Martin and J. I. Siepmann, J. Phys. Chem. B, 1998, 102, 2569-2577.

62 S. Calero, D. Dubbeldam, R. Krishna, B. Smit, T. J. H. Vlugt, J. F. M. Denayer, J. A. Martens and T. L. M. Maesen, J. Am. Chem. Soc., 2004, 126, 11377-11386.
63 D. Dubbeldam, E. Beerdsen, T. J. H. Vlugt and B. Smit, J. Chem. Phys., 2005, 122, 224712.

64 M. Schenk, S. Calero, T. L. M. Maesen, T. J. H. Vlugt, L. L. van Benthem, M. G. Verbeek, B. Schnell and B. Smit, J. Catal., 2003, 214, 88-99.

65 C. Gucuyener, J. van den Bergh, J. Gascon and F. Kapteijn, J. Am. Chem. Soc., 2010, 132, 17704-17706.

66 J. van den Bergh, C. Gucuyener, E. A. Pidko, E. J. M. Hensen, J. Gascon and F. Kapteijn, Chem.-Eur. J., 2011, 17, 8832-8840.

67 E. J. Ras, M. J. Louwerse, M. C. Mittelmeijer-Hazeleger and G. Rothenberg, Phys. Chem. Chem. Phys., 2013, 15, 4436-4443. 